\title{
ASSESSING HYDROLOGICAL DYNAMICS OF GUYANA'S NORTH RUPUNUNI WETLANDS USING SENTINEL-1 SAR IMAGERY CHANGE DETECTION ANALYSIS ON GOOGLE EARTH ENGINE
}

\author{
Javier Ruiz-Ramos ${ }^{(1)}$,Andrea Berardi ${ }^{(1,3)}$, Armando Marino ${ }^{(2)}$, \\ Deepayan Bhowmik ${ }^{(2)}$, Matthew Simpson ${ }^{(3,4)}$
}

\author{
(1) The Open University, School of Engineering and Innovation, Milton Keynes, UK. \\ ${ }^{(2)}$ Faculty of Natural Sciences, The University of Stirling. Stirling, UK. \\ ${ }^{(3)}$ Cobra Collective CIC, Egham, Surrey, UK. \\ (4) 35 percent, Stroud, Gloucestershire, UK.
}

\begin{abstract}
Wetlands are among the most productive natural ecosystems in the world, generally being important biodiversity hotspots. However, the complex nature of these landscapes together with the fragile and dynamic relationships among the organisms inhabiting these regions, make wetland ecosystems especially vulnerable to environmental disturbance, such as climate change. Thus, developing new automated systems which allow the continuous monitoring and mapping of wetland dynamics is crucial for informing decision-making and preserving their natural health. Synthetic Aperture Radar (SAR) sensors deployed on satellite platforms such as SENTINEL-1 are increasingly recognized as essential for wetland monitoring. The high sensitivity of SAR sensors to environmental variation makes them particularly suitable for investigating the hydrological processes occurring within these ecosystems.

The main objective of this paper is to propose a rapid polarimetric SAR (PolSAR) change detection tool for monitoring and mapping the flood dynamics and environmental condition of the North Rupununi region, Guyana. By making use of dense Sentinel-1 timeseries data and the Google Earth Engine (GEE) platform, we were able to map temporal open water and temporal flooded vegetation areas in a continuous and near-real time basis. The outcomes derived from this study significantly contributed to identify the hydrological mechanisms of the region of study while providing essential and valuable information for rapid response and environmental impact assessment.
\end{abstract}

Index Terms - Change detection, SAR, PolSAR, flood monitoring.

\section{INTRODUCTION}

Wetlands are recognised to be among the most productive ecological systems and are critical for human survival [1].
Wetlands are naturally dynamic systems with seasonal hydrological fluctuations driving biological, chemical and physical processes. The interaction among wetland structural components and naturally occurring processes within these complex landscapes provides important ecosystem services such as food supply, climate change mitigation, water supply and purification [1], [2]. These benefits serve as a socioeconomic resource base for local communities [3]. Unfortunately, recent studies [1], [4], [5] indicate a loss of $87 \%$ of the world's wetlands since 1700 , in places where data exists, with accelerated loss occurring between 1970 and 2015 of $35 \%$, three times the rate of forest loss. In addition, remaining wetland ecosystems are expected to be lost and degraded further, as a result of frequent exposure to rapid changes driven by direct (e.g., wetland conversion to other land-uses such as agriculture and urban expansion) and indirect (e.g., climate change, agricultural and industrial pollution, species introductions) human impacts [6], [7]. This demonstrates the urgent need to develop new tools and methods that, through continuous monitoring and evaluation of wetland dynamics, allow for better informed and proactive management and protection. This can be achieved by taking advantage of the recent advancements in high spatial and temporal remote sensing imagery. However, a major challenge in the use of optical remotely sensed satellite imagery for exploring wetland surface water dynamics within tropical contexts is the extensive cloud cover during the wet season. On the other hand, Synthetic Aperture Radar (SAR) imagery emerges as the most valuable alternative as its active nature (nondependency of external source of light) allows it to penetrate cloud cover. In addition to the advantage of their imaging capacity with high cloudiness or at night, the high sensitivity of these sensors to variations in the physical properties of objects on the Earth's surface enhances the potential of this technology for environmental monitoring applications. Radar signals are highly influenced by three main physical parameters which are inherent of any object or surface target: geometry, roughness and moisture content. Natural

(C) 2020 IEEE. Personal use of this material is permitted. Permission from IEEE must be obtained for all other uses, in any current or future media, including reprinting/republishing this material for advertising or promotional purposes, creating new collective works, for resale or redistribution to servers or lists, or reuse of any copyrighted component of this work in other works. 
disturbances, such as flood events, significantly alter these parameters, thus producing a variation in backscatter values which can be detected using various change detection techniques[8]. Therefore, by focusing the analysis on the investigation of SAR signal amplitude variation, it is possible to detect the spatiotemporal changes such as surface water dynamics within wetland ecosystems.

This paper focuses on generating the first hydrological/flooding dynamic study for the North Rupununi region, Guyana. In our research, we therefore set out to explore the accuracy of surface water dynamics monitoring applying change detection analysis of dense Sentinel-1 SAR timeseries data within the Google Earth Engine Platform.

\section{STUDY AREA}

The North Rupununi Wetlands are situated in the southern interior of Guyana, South America, and support a high terrestrial and freshwater biodiversity. This rich biodiversity is not only important for conservation but also supplies Indigenous communities with a range of livelihood activities, including subsistence fishing and ecotourism. The North Rupununi Wetlands are characterised by low topography and seasonal flooding and have recently been the target of major agro-business interest particularly for rice cultivation. Guyana is a low-income country, and pressure to convert natural habitats into large-scale industrial farms and associated infrastructure, especially access roads, is having an increasing impact on the North Rupununi Wetlands. With these land use transformations there is the increasing risk of water pollution and habitat destruction, resulting in the loss of species in general and ecological connectivity in particular.

Increasing pressures from climate change (e.g., the increase in extreme weather events including flooding and droughts) is further threatening biodiversity and Indigenous populations in the region. The only way to make sure further development is sustainable is to carry out large-scale assessments, which require periodic surveys. Although the North Rupununi Wetlands are spectacular ecosystems, surveying them is very time demanding due to the remoteness and the logistic difficulties of reaching these vast areas during the peak floods in the wet season (April to September) when most roads become impassable. Additionally, many features are more easily visible from above (e.g., location and distribution of surface water). Indigenous communities and key decision makers are therefore in need of inexpensive, simple and rapid methodologies that are able to provide periodic surveys of the hydrological and ecological status of their surrounding landscape. Our research is therefore an attempt to demonstrate that applying change detection analysis of dense Sentinel-1 SAR timeseries within the Google Earth Engine Platform could be a key tool in achieving this.

\section{DATA}

We used a dense timeseries of GRD Sentinel 1 images acquired for the period of study (01/01/2019 - 31/12/2019) at a 12-day temporal resolution and with the same orbit path (164). The use of a 12-day time window instead of 6 days responds to the decision to work with a single mode of acquisition (ascending) and orbit. Thus, confidence in detecting change due to environmental factors will be greater, since the combined use of images obtained with different orbits (multiorbital approach) could lead to misclassifications caused by imaging positions[9]. The resulting timeseries was formed by a total of 30 dual polarisation (VV, VH) SAR acquisitions, which were already automatically pre-processed in GEE using the following steps: 1. Thermal Noise Removal, 2. Radiometric Calibration, 3. Terrain Correction and 4. Linear to $\mathrm{dB}$ transformation.

In order to evaluate the accuracy of our surface water detection, ground-truth data was collected by a field team on eight fieldwork campaigns carried out during the wet season. Handheld GPSs (position accuracy +- 9m) were used to map the land/water edge (up to $600 \mathrm{~m}$ in length), for four distinct sites, representing different hydrological subcatchments within the North Rupununi wetlands.

\section{METHODS}

For the first step, we focused on differentiating the precise timing of the 2019 dry and wet season of our study region, determined in terms of the presence of extensive areas of surface water (and therefore low backscatter values), rather than actual rainfall. A preliminary exploration of the backscatter time series of both polarisation channels (VV, $\mathrm{VH}$ ), allowed us to separate the periods of the dry and wet seasons, which allowed us to precisely identify the beginning (05/05/2019) and the end (08/12/2019) of the 2019 wet season. Once the seasons were separated, we used all the images acquired during the dry season to compute a multi-temporal mean composite image that was used as a reference for the subsequent change detection analysis. The last data preparation step was the speckle filter process. All images of the wet season were filtered by using a circular mean filter (boxcar) of 20 meter radius. The speckle filter, which removed a significant number of false positives, enabled the generation of smoother images through a notable reduction of noise.

For the change detection analysis, we made use of the logratio method for comparing each of the images acquired during the wet season with the reference dry mean composite. The change detection analysis was carried out using the cross-polarisation channel (VH) as it showed a greater level of separability between dry and wet seasons. Compared to other subtraction techniques, the log ratio method has been widely used for change detection since it mitigates the influence of radiometric and calibration errors 
[10]. This approach relies on the comparison of backscatter values of two images acquired at different time, in this case, before and during the flood events. Using a threshold based on the histograms of regions, surface water and flooded vegetation areas were masked out.

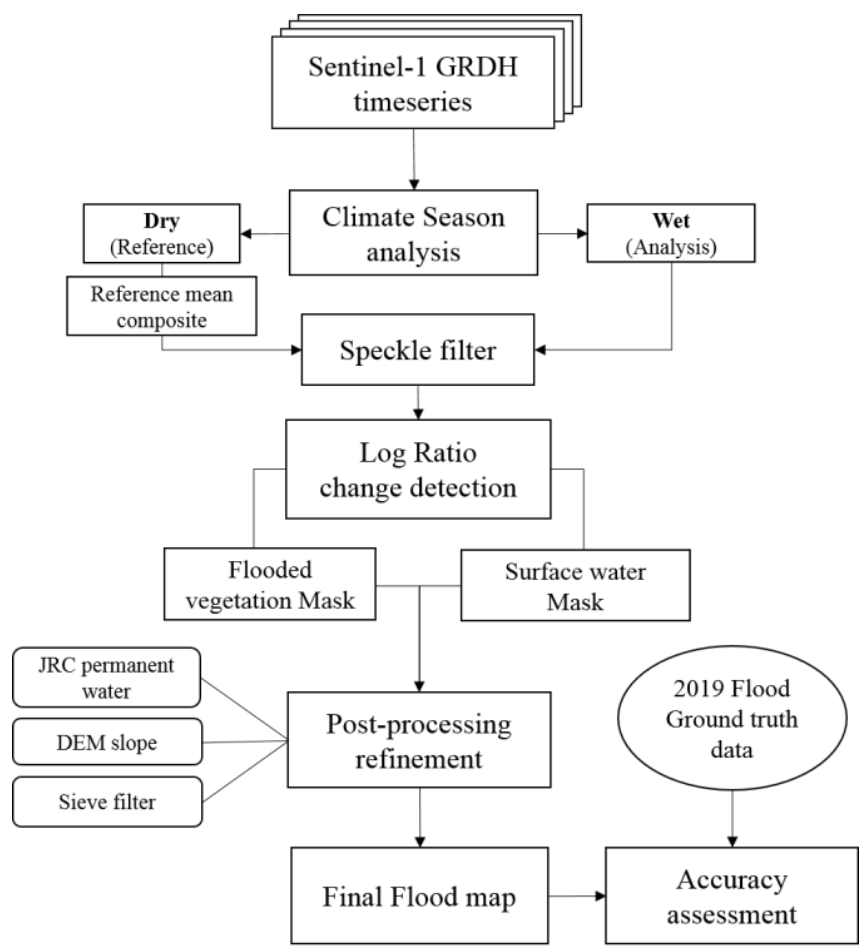

Figure 1. Flow chart of the proposed SAR Sentinel-1 flood change detection analysis.

Once surface water and flooded vegetation masks were obtained for each of the wet season images, these were refined using the method proposed by UN-Spider [11], which uses additional EO datasets to reduce the presence of false positives within the masks. This process followed three steps: 1. Permanent water bodies addition, 2. DEM-slope analysis and 3. Sieve filter. For the first process JRC global surface water map was used for adding all permanent water bodies (> 10months/year). Secondly, WWF HydroShed DEM allowed us to remove all flooded pixels located in steep terrain (slope $>5 \%$ ), since we assume that water must flow on terrains with such characteristics. Last, the sieve connectivity filter helped us to eliminate those smaller and isolated flooded areas, generally caused by noise or geometric distortions. All flooded pixels connected to 15 or fewer neighbours were removed.

Finally, an accuracy assessment was carried to validate the results obtained from the change detection analysis. By making use of the surface water ground truth data, collected during the 2019 wet season, a spatial proximity analysis was carried out in order to investigate the accuracy of the surface water masks.

\section{RESULTS}

\subsection{Sentinel-1 SAR flood change detection}

An initial exploration of the backscatter timeseries on different land cover classes helped us to analyse the SAR signal behaviour during the wet season (see figure 2). Wetland areas showed a progressive decrease in the backscatter intensity, which begun with the first rains and remained stable for the entire wet season. These low intensity values, typical of surface water areas, correspond to a change in the dominant backscatter mechanism from surface scattering, with a strong returned signal, to specular reflection. In contrast, open vegetation areas showed temporary increases in the signal intensity which coincide with severe precipitation events that occurred during the wet season. These fluctuations in the backscatter intensity allowed us to assess the hydrological dynamics of the region by analysing the main flooding mechanisms. Lastly, the forest areas showed a very stable trend throughout the year, while the cultivated areas (rice) showed a significant decrease as a result of the paddy fields flooding and a progressive increase in the backscatter intensity led by subsequent plant growing stages.
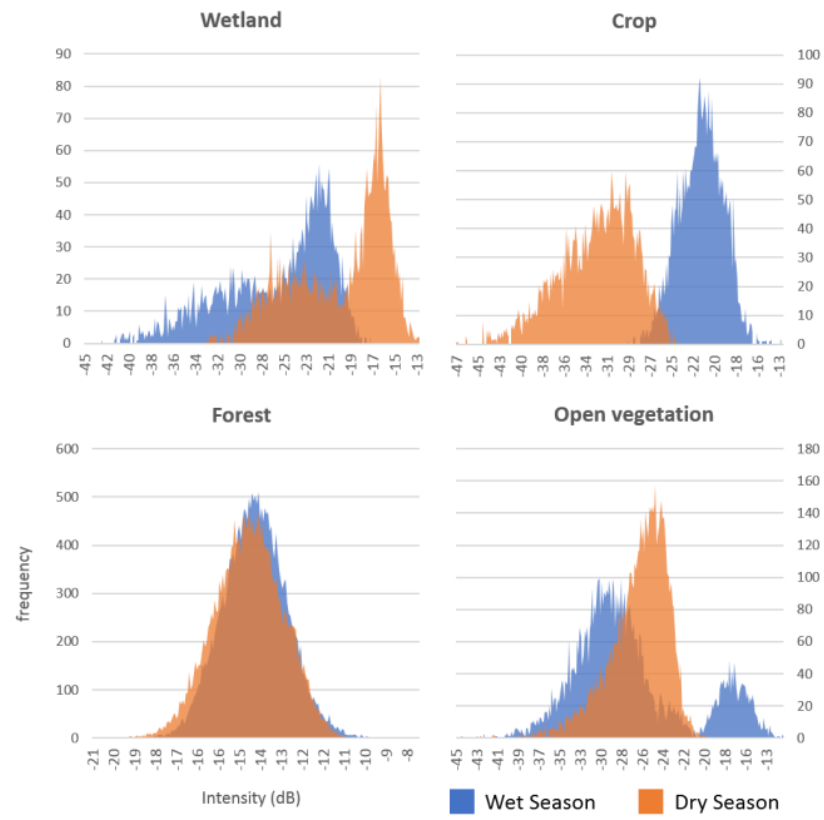

Figure 2. Comparison the SAR-Sentinel-1 VH channel backscatter behavior on Land cover classes for the wet and dry seasons. Dry season values were obtained using the reference dry mean composite while for the wet season we used the peak flood image (22/06/2019).

The flood masks were extracted based on the SAR signal backscatter behavior observed for the different land classes (see figure 3). Difference images resulted from the log-ratio analysis were thresholded to obtain the surface water (reduction $>1.20 \mathrm{~dB}$ ) and flooded vegetation (increase $>1.6$ dB) masks. 

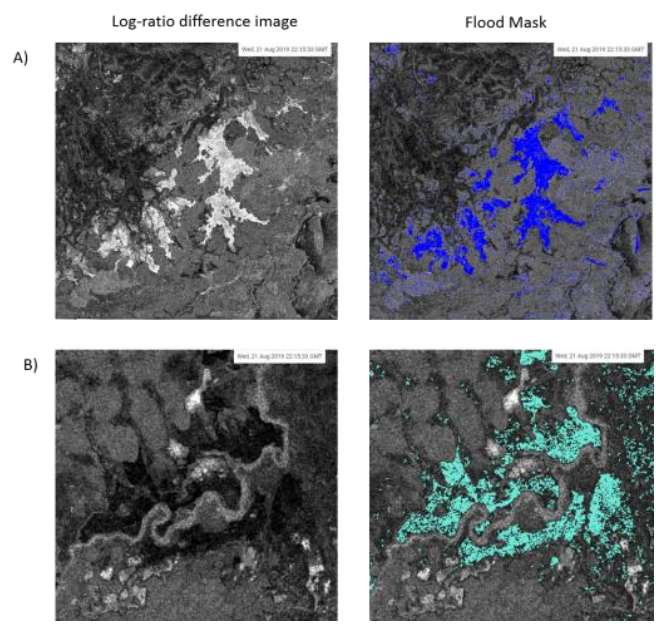

Figure 3. Example of the Log-ratio difference images and flood masks obtained for the peak flood date (22/06/2019). Top row corresponds to wetland areas, while bottom row illustrates a rice crops region on the banks of the Ireng river.

\subsection{North Rupununi Hydrological model}

This research has served to further refine the understanding of the hydrological mechanisms for flooding and water movement across the North Rupununi Wetlands (see figure 4). In order to provide an accurate representation of the flooding dynamics of the study area, the proposed flood detection analysis was repeated for the 2017, 2018 wet seasons. The interpretation of the recurrent trends observed for the studied years demonstrated the complex interactions of five hydrological mechanisms supporting water levels within the North Rupununi Wetland. Besides the near-realtime flood change detection capabilities, the proposed tool has also provided useful guidance for new landscape management plans.

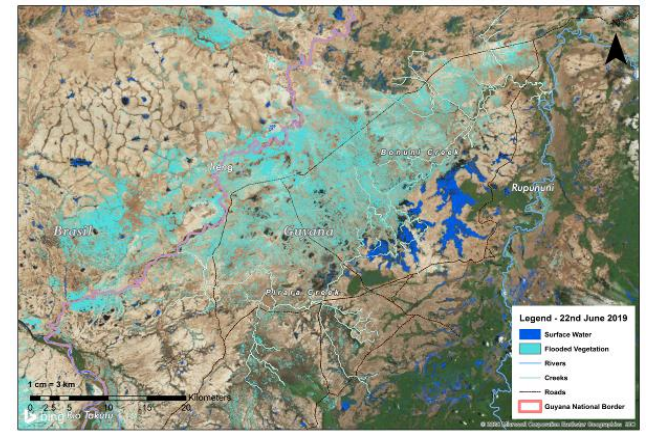

Figure 4. Example of a flood map obtained for the North Rupununi region on $22^{\text {nd }}$ June 2019.

\section{CONCLUSIONS}

The use of polarimetric change detection analysis on Sentinel-1 synthetic aperture radar data offered rapid about the hydrological dynamics of the North Rupununi natural wetlands. The surface water ground truth data allowed us to validate the SAR-based change detection analysis results.
This research highlights the benefits derived from the use of high temporal SAR timeseries for near-real time surface water monitoring. The computing capabilities, extensive data archive and user-friendly environment of Google Earth Engine confirm its position as a powerful platform for the development of new environmental remote sensing tools.

Acknowledgements: We acknowledge the support of WWFGuianas, The Open University Space SRA and University of Stirling (through GCRF SPARK funding). Data courtesy of ESA.

\section{REFERENCES}

[1] M. Finlayson et al., "Ramsar Convention on Wetlands," Gland, Switzerland, 2018.

R. Costanza et al., "The value of the world's ecosystem services and natural capital," Nature, vol. 387, no. 6630, pp. 253-260, May 1997.

[3] N. C. Davidson, A. A. Van Dam, C. M. Finlayson, and R. J. McInnes, "Worth of wetlands: Revised global monetary values of coastal and inland wetland ecosystem services," Mar. Freshw. Res., vol. 70, no. 8, pp. 1189-1194, Mar. 2019.

[4] N. C. Davidson, "How much wetland has the world lost? Long-term and recent trends in global wetland area," Mar. Freshw. Res., vol. 65, no. 10, pp. 934-941, 2014.

[5] L. Dinesen et al., "Trends in the ecological character of the world's wetlands," Mar. Freshw. Res., vol. 71, pp. 127-138, 2019.

[6] L. Ballanti, K. Byrd, I. Woo, and C. Ellings, "Remote Sensing for Wetland Mapping and Historical Change Detection at the Nisqually River Delta," Sustainability, vol. 9, no. 11, p. 1919, Oct. 2017.

R. J. McInnes, N. C. Davidson, C. P. Rostron, M. Simpson, and C. M. Finlayson, "A Citizen Science State of the World's Wetlands Survey," Wetlands, pp. 1-17, Jan. 2020.

[8] E. Podest, "Conceptos Básicos del Radar de Apertura Sintética,” 2017. Accessed: Aug. 28, 2018. [Online]. Available: http://arset.gsfc.nasa.gov@nasaarset.

S. Mahdavi, M. Amani, and Y. Maghsoudi, "The effects of orbit type on synthetic aperture RADAR (SAR) backscatter," Remote Sens. Lett., vol. 10, no. 2, pp. 120 128, 2019.

[10] D. Lu, P. Mausel, E. Brondízio, and E. Moran, "Change detection techniques," Int. J. Remote Sens., vol. 25, no. 12, pp. 2365-2401, Jun. 2004.

[11] UN-SPIDER, "Step by Step: Recommended Practice Flood Mapping.” http://www.un-spider.org/advisorysupport/recommended-practices/recommended-practiceflood-mapping/step-by-step (accessed Apr. 06, 2020). 